\title{
Microhabitat choice and polymorphism in the land snail Theba pisana (Müller)
}

\author{
W. N. Hazel* and \\ M. S. Johnson $\dagger$
}

* Department of Biological Sciences, DePauw University, Greencastle, IN 46136, U.S.A. + Department of Zoology, The University of Western Australia, Nedlands, Western Australia 6009, Australia.

Associations between microhabitat, shell banding and apex colour were examined in the land snail Theba pisana. Snails on their summer aestivation sites were sampled from a transect that included a relatively sheltered $A$ cacia habitat and a more exposed open habitat. The frequencies of fully banded snails and snails with dark apexes, as well as the intensity of banding in fully banded snails, were lower in the open habitat than in the Acacia habitat. No differences in microhabitat relative to shell phenotypes were found in samples from the open habitat. However, significant differences in microhabitat were found between effectively unbanded and fully banded snails in the Acacia habitat, with effectively unbanded snails more common in the exposed Acacia canopy and fully banded snails more common beneath the canopy. Air temperatures in the Acacia canopy were consistently higher than below the canopy, while body temperatures of living fully banded and unbanded snails in sunlight indicated that fully banded snails heat more rapidly than do unbanded snails. These results suggest a potential role for both climatic selection and adaptive plasticity in microhabitat choice in the maintenance of variation in shell banding.

\section{INTRODUCTION}

Natural selection in heterogeneous environments is more likely to result in the maintenance of genetic polymorphism if different genotypes are able to choose the habitats in which they are most fit (Taylor, 1976; Powell and Taylor, 1979). In land snails polymorphic for shell banding, such as Cepaea nemoralis, habitat choice is thought to be important in maintaining the polymorphism, since banded shells absorb more solar energy than do unbanded shells and the snails modify their exposure to the sun behaviourally (Jones, 1973; 1982).

The Mediterranean land snail Theba pisana (Müller) is polymorphic for shell banding and is abundant in introduced colonies occurring along the coastal dunes in southern Western Australia. In the City Beach population of $T$. pisana, near Perth, Western Australia, there is a strong association between banding morph frequency and habitat, with frequencies of fully banded snails being greatest in the sheltered Acacia habitat and effectively unbanded snails more common in the more exposed open areas (Johnson, 1980). The strength of the association between banding and habitat is probably due to the combined effects of climatic selection within habitats and the differential seasonal migration of fully banded and effectively unbanded snails between habitats. Because of their thermal properties, unbanded snails are presumably favoured in open habitats, and with the onset of summer, banded snails in the open habitat preferentially move into the Acacia habitat, setting up a steep cline in morph frequencies at the habitat boundary (Johnson, 1980; 1981).

During the summer, microhabitat choice by $T$. pisana, such as climbing on host plants to choose resting sites that are sheltered from the sun and wind, and orientation of the shell to facilitate heat flow is seen as an adaptation that allows the snails to avoid high environmental temperatures (McQuaid et al., 1979; Cowie, 1985). Consequently, we might expect differences in summer resting sites and shell orientation to be related to differences in shell banding. Thus, this study examines the degree to which banded and unbanded snails in the City Beach population differ in their summer resting sites, and whether those differences are important in altering the thermal relationship of the animals in sunlight. 


\section{MATERIALS AND METHODS}

\section{Shell variation}

The City Beach population of T. pisana is polymorphic for shell banding and apex colour. The variation in shell banding in $T$. pisana has been described elsewhere (Johnson, 1980; Cain, 1984; Cowie, 1984). In general, the shell is white with varying numbers of bands, which may be either uniformly yellowish-buff, or broken longitudinally, and often transversely, into a series of discrete brown bandlets. Variation in shell phenotype in $T$. pisana is controlled by a minimum of three loci with some genotypes having variable penetrance and expressivity, resulting in a complex array of phenotypes (Cain, 1984; Cowie, 1984). The colour of the shell apex is either pale or dark, depending on alleles at a single locus with the pale dominant to dark. This locus is closely linked to the locus with the greatest effect on banding (Cain, 1984; Cowie, 1984).

As with previous studies of $T$. pisana at City Beach and elsewhere, we adopted a functional classification of snails as either fully banded or effectively unbanded. The former category includes all snails with bands present above the midline, while the latter includes snails with bands absent above the midline. We also noted apex colour and the number of bandlets present in each band on those snails classified as fully banded. Following Johnson (1980), the last $90^{\circ}$ of the outermost whorl was ignored in scoring the shells.

\section{Study area and sampling}

The study site was an area of coastal dunes at the southern boundary of City Beach, Western Australia $\left(31^{\circ} 58^{\prime} \mathrm{S} ; 11^{\circ} 45^{\prime} \mathrm{E}\right)$, described in Johnson $(1980 ; 1981)$. A total of 524 adult snails were sampled between January and March, 1989, from a transect $0.25 \mathrm{~m}$ wide and $47 \mathrm{~m}$ long running parallel to the transect described by Johnson (1981). Thus, the transect spanned the boundary of the Open I and Acacia I areas of Johnson (1980), with approximately $22 \mathrm{~m}$ at the eastern end of the transect dominated by Acacia bushes 1 to $2 \mathrm{~m}$ tall. In contrast, the vegetation in the western $25 \mathrm{~m}$ of the transect was dominated by a low growing succulent, Tetragonium decumbencens, and Pelargonium capitatum; these plants averaging about $20 \mathrm{~cm}$ in height.

As each snail was examined, the following information was recorded, along with its banding phenotype and apex colour:

(1) host plant species
(2) host plant height

(3) part of plant on which snail was resting (leaf, stem, etc.)

(4) height of snail

(5) for snails resting on vertical stems, or on plant parts attached to vertical stems, the quadrant $(\mathrm{N}, \mathrm{E}, \mathrm{S}, \mathrm{W})$, relative to the stem, in which the snail was positioned

(6) whether the snail shell was oriented vertically or horizontally

(7) for snails on Acacia bushes, whether the animal was under the canopy or in the canopy. Comparisons of resting site characteristics were made within and between the Acacia and open sections of the transect using chi square tests or $t$ tests. Allowances were made for the simultaneous testing of several hypotheses using the method of Jensen et al. (1968).

\section{Temperature measurements}

Measurements of air temperatures in the field and snail body temperatures in sunlight were made using a Type $\mathrm{K}$ thermocouple meter (R.S. Components, Ltd., Stock No. 611.234). Air temperatures in the field were measured at ten different positions in the Acacia canopy and below the canopy. For these measurements the thermocouple was covered with a small piece of aluminium foil. Snail body temperatures were measured in six pairs of banded and unbanded snails of similar size. Measurements were made before and after exposure to sunlight. For these measurements, snails were positioned on pads of white modeling clay so that the apex was directed towards the sun. With the exception of a small opening approximately $1 \mathrm{~mm}$ ) through which the thermocouple was passed, the shell apertures were completely sealed with white modeling clay. After more than two minutes exposure to direct sunlight the snails became sufficiently aroused that they were able to remove the modeling clay sealing their apertures. Since this resulted in evaporative cooling, temperature measurements were taken after only two minutes exposure to sunlight. To minimize possible effects of prior acclimation, the snails used in these experiments were collected from within a $3 \mathrm{~m}$ radius within the Acacia habitat.

\section{RESULTS}

\section{Habitat associations}

Shell banding and apex colour were polymorphic throughout the transect, but fully banded snails 
and snails with dark apexes were more common in the Acacia section of the transect than in the open section $(53 \cdot 6 \pm 3 \cdot 2$ per cent of the snails in the open were fully banded compared with $77 \cdot 7 \pm$ 2.5 per cent in the Acacia; $19.4 \pm 2.6$ per cent of the snails in the open had dark apexes compared with $34 \cdot 1 \pm 2 \cdot 8$ per cent in the Acacia). Throughout the transect there was a strong association between shell banding and apex colour: 40 per cent of fully banded snails had a dark apex compared with 2 per cent of the effectively unbanded snails $(P<$ 0.01 , chi-square test). In addition, fully banded snails found in the open area of the transect had less intense bands than snails in the Acacia section of the transect, as measured by total number of bandlets above the midline (the average number of bandlets for fully banded snails in the open was 3.56 , compared with 4.85 for fully banded snails in the Acacia $(P<0 \cdot 01, t$-test $))$.

\section{Microhabitat associations}

No differences in microhabitat were found between morphs in the open habitats. Thus we pooled the banded and unbanded snails from the open area for comparison with snails in the Acacia habitat. Regardless of banding or habitat, there was an excess of snails in the western quadrant of the host plants (table 1). For fully banded snails in the Acacia, this excess was due to a corresponding avoidance of the northern quadrant. In contrast, the effectively unbanded snails in the Acacia showed a strong avoidance of the eastern quadrant, and an attraction to the southern and western quadrants. Although the distributions of both fully banded and effectively unbanded snails in the Acacia habitat did not differ significantly, the sig- nificant difference between the distributions of effectively unbanded snails in the Acacia and snails in the open suggest that the effect of habitat is smaller for the fully banded group (table 1).

The orientation of the snails also differs between morphs and habitats. Although most of the snails were oriented vertically, this tendency was strongest for the fully banded snails in the Acacia, and weakest for the effectively unbandeds in the Acacia (table 2). The proportion of vertically oriented snails in the open habitat, while not significantly different from either class of snails in the Acacia, was more similar to that of the fully bandeds in the Acacia than to that of the effectively unbanded snails in the Acacia.

A major difference between the two habitats is the height of the vegetation (Johnson, 1980). The snails make use of the height provided by the Acacia bushes, where the mean resting heights of snails in the Acacia was $114.4 \pm 7.4 \mathrm{~cm}$ for effectively unbanded snails and $122.9 \pm 4.0 \mathrm{~cm}$ for fully banded snails compared with $20 \cdot 8 \pm 1 \cdot 3 \mathrm{~cm}$ for effectively unbanded snails and $17 \cdot 8 \pm 1 \cdot 0 \mathrm{~cm}$ for fully banded snails in the open. Banding did not influence the average height of the resting sites, but did affect the distribution of snails within the Acacia bushes. Only 6 per cent of the fully banded snails in the Acacia were on leaves instead of branches, while 21 per cent of the effectively unbandeds were found on leaves (table 3). As a result, effectively unbanded snails were also much more likely to be in the canopy of the Acacia bushes (table 4).

There were no differences in resting sites of snails with pale versus dark apexes in either habitat. There was, however, a tendency for fully banded snails in the Acacia canopy to have fewer

Table 1 Numbers of snails (proportions in parentheses) on the four quadrants of vertical host plants for all snails in the open section of the transect and for fully banded and effectively unbanded snails in the Acacia portion of the transect. Asterisks indicate a significant difference $(P<0.05)$ from random. Results with the superscript "a" are significantly different from each other $(P<0.05)$

\begin{tabular}{|c|c|c|c|c|c|}
\hline \multirow[b]{2}{*}{ Sample } & \multicolumn{5}{|c|}{ Quadrant on host } \\
\hline & $\mathbf{N}$ & $\mathrm{E}$ & $\mathrm{S}$ & W & Total \\
\hline \multicolumn{6}{|l|}{ Open habitat } \\
\hline All snails & $\begin{array}{l}59 \\
(0 \cdot 26)\end{array}$ & $\begin{array}{l}43 \\
(0 \cdot 18)\end{array}$ & $\begin{array}{l}38 \\
(0 \cdot 17)\end{array}$ & $\begin{array}{l}88 \\
(0 \cdot 39)\end{array}$ & $228^{* a}$ \\
\hline \multicolumn{6}{|l|}{ Acacia habitat } \\
\hline Fully banded snails & $\begin{array}{l}30 \\
(0 \cdot 15)\end{array}$ & $\begin{array}{l}42 \\
(0 \cdot 22)\end{array}$ & $\begin{array}{l}53 \\
(0 \cdot 27)\end{array}$ & $\begin{array}{l}70 \\
(0 \cdot 36)\end{array}$ & $195^{*}$ \\
\hline Effectively unbanded snails & $\begin{array}{l}11 \\
(0 \cdot 18)\end{array}$ & $\begin{array}{c}4 \\
(0.07)\end{array}$ & $\begin{array}{l}24 \\
(0 \cdot 39)\end{array}$ & $\begin{array}{l}22 \\
(0 \cdot 36)\end{array}$ & $61^{* a}$ \\
\hline
\end{tabular}


Table 2 Numbers of snails (proportions in parentheses) oriented vertically and horizontally for all snails in the open section of the transect and for fully banded and effectively unbanded snails in the Acacia section of the transect. Results marked with an asterisk are significantly different from each other $(P<0 \cdot 05)$

\begin{tabular}{llll}
\hline & \multicolumn{2}{l}{ Orientation } & \\
\cline { 2 - 3 } Sample & Vertical & Horizontal & Total \\
\hline $\begin{array}{l}\text { Open habitat } \\
\text { All snails }\end{array}$ & $199(0.84)$ & $38(0.16)$ & 237 \\
$\begin{array}{l}\text { Acacia habitat } \\
\quad \text { Fully banded snails }\end{array}$ & $201(0.90)$ & $22(0.10)$ & $223^{*}$ \\
$\quad$ Effectively unbanded snails & $47(0.73)$ & $17(0.27)$ & $64^{*}$ \\
\hline
\end{tabular}

Table 3 Numbers of banded and unbanded snails (proportions in parentheses) on branches and leaves of Acacia bushes in the Acacia portion of the transect. The distributions are significantly different by chi-square test $(P<0.01)$

\begin{tabular}{lll}
\hline & \multicolumn{2}{l}{ Resting site } \\
\cline { 2 - 3 } Sample & Branches & Leaves \\
\hline Fully banded snails & $175(0.94)$ & $12(0.06)$ \\
Effectively unbanded snails & $42(0.79)$ & $11(0.21)$ \\
\hline
\end{tabular}

Table 4 Numbers of banded and unbanded snails (proportions in parentheses) in the Acacia canopy and under the Acacia canopy for snails on Acacia bushes in the Acacia portion of the transect. The distributions are significantly different by chi-square test $(P<0.05)$

\begin{tabular}{lcc}
\hline & \multicolumn{2}{c}{ Resting site } \\
\cline { 2 - 3 } Sample & Under canopy & In canopy \\
\hline Fully banded snails & $143(0.76)$ & $44(0.24)$ \\
Effectively unbanded snails & $31(0.58)$ & $22(0.42)$ \\
\hline
\end{tabular}

bandlets above the midline compared to fully banded snails beneath the canopy, but this difference was not significant $(P=0 \cdot 16, t$-test $)$.

\section{Temperature measurements}

When fully banded and unbanded snails were exposed in pairs to direct sunlight for $2 \mathrm{~min}$ the change in body temperature of the banded snail was greater than that of the unbanded snail in all six comparisons $(P<0.05$, sign test; the average temperatures of banded snails before and after exposure to sunlight were $21 \cdot 71 \pm 0.09^{\circ} \mathrm{C}$ and $22.96 \pm 0.29^{\circ} \mathrm{C}$, respectively, compared with $21 \cdot 71 \pm 0 \cdot 24^{\circ} \mathrm{C}$ and $22 \cdot 70 \pm 0 \cdot 56^{\circ} \mathrm{C}$, respectively, for unbanded snails).
In all ten pairwise comparisons of air temperatures in and below the Acacia canopy the temperature in the canopy was greater than that below ( $P<0.01$, sign test; the average temperature in the canopy was $30 \cdot 88 \pm 0.56^{\circ} \mathrm{C}$ compared with $29 \cdot 12 \pm 0 \cdot 39^{\circ} \mathrm{C}$ below the canopy).

\section{DISCUSSION}

The results of this study confirm the strong association of shell banding and habitat previously observed for T. pisana in the City Beach population (Johnson, 1980; 1981). Apex colour and the number of bandlets were not examined in the earlier studies, and their associations with habitat indicate that there is a concerted change from pale shells in the open habitat to dark shells in the Acacia. A likely explanation for this association is climatic selection, favouring snails with darker shells in cooler or shady environments and snails with lighter coloured shells in warmer or sunny areas. Such selection has been implicated as an important cause of large differences in morph frequencies between geographically separated populations, as well as between snails occupying different habitats within populations (Jones et al., 1977; Heller 1981). Although providing a possible explanation for the difference in morph frequencies between habitats, such selection does not explain the persistence of the polymorphism within each habitat. Habitat choice would contribute to such persistence in a heterogeneous environment and earlier work showed that at the habitat boundary fully banded $T$. pisana preferentially select the Acacia habitat for summer aestivation sites. The results reported here indicate that significant differences in the frequencies of fully banded and effectively unbanded $T$. pisana can occur even between different microhabitats within the same 
habitat, and that characteristics of the resting sites of different morphs can differ within and between habitats.

Although $T$. pisana is normally inactive though the dry summer months, periods of unseasonable rain during this study resulted in movement of the snails. It is therefore extremely unlikely that the differences in resting sites are a consequence of selective mortality between the time at which the snails chose their resting sites and the time of observation. Instead, the differences in resting sites between fully banded and effectively unbanded snails result from microhabitat choice.

Not all of the differences in microhabitat choice are easy to interpret without additional data. It is not clear, for example, why the snails preferred the western quadrants, nor why effectively unbanded snails in the Acacia should avoid the eastern quadrant. Similarly, the significance of variation in vertical or horizontal orientation, while not obvious, may be related to habitat and phenotype specific differences in the importance of substrate heat flow through the basal whorl air space (McQuaid et al. 1979). Regardless of their basis, these behavioural differences indicate that habitat choice must be considered in attempts to interpret the banding polymorphism.

For microhabitat choice to enhance the maintenance of polymorphism, individuais of different genotypes must choose the microhabitats in which they are most fit (Taylor, 1976; Powell and Taylor, 1979). Some of the behavioural differences between banding phenotypes are easily interpreted in this context because they parallel the association of morph frequencies with habitat observed on a larger scale. The preference of effectively unbanded snails and fully banded snails with fewer bandlets for leaves and the canopy of the Acacia bushes parallels their higher frequency in the open habitat. Measurements of air temperatures in and below the Acacia canopy confirm that the canopy is analogous to the hotter open habitat, and suggest how the adpative choice of microhabitat could be achieved. The measurements of body temperatures of living snails in sunlight show that fully banded snails heat more rapidly than do unbanded snails. Assuming that fully banded and effectively unbanded $T$. pisana are equally susceptible to the lethal and sublethal effects of high internal temperatures, the tendency of banded snails to choose resting sites below the canopy is clearly adaptive because of the lower air temperature and increased shading.

Behavioural plasticity is the primary mode of thermoregulation by invertebrates (Henwood, 1975), and T. pisana use light, wind and thermal gradients in choosing their resting sites (McQuaid et al., 1979; Cowie, 1985). Thus, it is likely that the differences in resting sites of banded and unbanded morphs are a consequence of differences in their shell banding phenotypes and how these affect body temperature, rather than a pleiotropic effect of the genes controlling shell banding.

Phenotypic plasticity, whether morphological or behavioural, is thought to evolve as an adaptation to environmental heterogeneity (Thoday, 1953). In the case of $T$. pisana, phenotypic plasticity in microhabitat choice is an adaptation to environmental heterogeneity that affects body temperature. Differences between banding morphs in their choice of microhabitats are probably a direct behavioural compensation for the influence of their banding phenotypes on internal temperatures. Since thermal gradients in the Acacia bushes provide a range of microhabitats on a very fine scale, microhabitat choice along these gradients results in a reduction in selection amongst banding morphs, and a greater likelihood that polymorphism will persist.

While providing a partial explanation for the maintenance of the banding polymorphism, the observed differences in choice of microhabitats leave some important questions unanswered. It is not surprising that behavioural differences between morphs were found in the Acacia but not in the open, because the relative simplicity of the latter provides less opportunity for choice of microhabitats. Nevertheless, the polymorphism persists in the open habitat, even in areas well isolated from the Acacia (Johnson, 1980). Since summer temperatures greater than $40^{\circ}$ are common in the dunes at City Beach, the potential benefits of pale shells are obvious. The persistence of banding in the open habitat suggests that there must be some compensating benefit of dark shells, even in the exposed areas, and invites ecophysiological study of the banding morphs.

Acknowledgements We thank Dr P. C. Withers for use of the thermocouple. This research was funded in part by a grant from the John and Janice Fisher Fund for Faculty Excellence at DePauw University. Research facilities were provided by the Department of Zoology of The University of Western Australia.

\section{REFERENCES}

CAIN, A. J. 1984. Genetics of some morphs in the land snail Theba pisana. Malacologia, 25, 381-411.

COWIE, R. H. 1984. Ecogenetics of Theba pisana (Pulmonata: Helicidae) at the northern edge of its range. Malacologia, $25,361-380$. 
COWIE, R. H. 1985. Microhabitat choice and high temperature tolerance in the land snail Theba pisana (Mollusca: Gastropoda). J. Zool, Lond. (A), 207, 201-211.

HELLER, J. 1981. Visual versus climatic selection of shell banding in the landsnail Theba pisana in Israel. J. Zool, Lond., 194, 85-101.

HENWOOD, K. 1975. A field tested thermoregulation model for two diurnal Namib Desert tenebrionid beetles. Ecology, $56,1329-1342$.

JENSEN, D. R., BEUS, G. B., AND STORM, G. 1968. Simultaneous statistical tests on categorical data. J. exp. Educ. 36, 46-56.

JOHNSON, M. S. 1980. Association of shell banding and habitat in a colony of the land snail Theba pisana. Heredity, 45, 7-14.

JOHNSON, M. S. 1981. Effects of migration and habitat choice on shell banding frequencies in Theba pisana at a habitat boundary. Heredity. 47, 121-133.

JONES, J. S. 1973. Ecological genetics and natural selection in molluscs. Science, 182, 546-552.
JONES, J, S. 1982. Genetic differences in individual behaviour associated with shell polymorphism in the snail Cepaea nemoralis. Nature, 298, 749-750.

JONES, J. S., LEITH, B. H. AND RAWLINGS, P. 1977. Polymorphism in Capaea: A problem with too many solutions? $A$ Rev. Ecol. Syst., 8, 109-143.

MCQUAID, C. M., BRANCH, G. M., AND FROST, P. G. H. 1979. Aestiavation behaviour and thermal relations of the pulmonate Theba pisana in a semi-arid environment. $J$. therm. Biol., 4, 47-55.

POWELL, J. R. AND TAYLOR, C. E. 1979. Genetic variation in ecologically diverse environments. Am. Scientist, 67, 590596.

TAYLOR, C. E. 1976. Genetic variation in heterogeneous environments. Genetics, 83, 887-894.

THODAY, J. M. 1953. Components of fitness. Symp. Soc. expl. Biol., 7, 96-113. 